\title{
Comparar: verbo transitivo; uma conversa com Jürgen Schriewer
}

Maria Angela Borges Salvadoril

Maurilane de Souza Biccas

\section{Resumo}

Professor e diretor do Centro de Educação Comparada da Universidade de Humboldt (Berlim, Alemanha), recentemente aposentado, Jürgen Schriewer é internacionalmente reconhecido por seus estudos em educação comparada. Foi também diretor da Faculdade de Educação daquela instituição e presidente da Sociedade de Educação Comparada da Europa. Como professor visitante, atuou em vários países, entre os quais França (Universidades René Descartes e Paris V), Japão (Universidade Waseda, em Tóquio) e Argentina (Universidade de San Andrés, em Buenos Aires). Esta entrevista busca oferecer ao leitor uma rara ocasião para conhecer um pouco mais a trajetória e o trabalho desse pesquisador que, há décadas focado nesta temática, trata aqui, de maneira mais informal, de matéria cada vez mais contemporânea e cara. Além de sua trajetória profissional e seu modo de inserção no campo da história da educação comparada, Schriewer compartilhou também impressões sobre os tempos e lugares pelos quais tem circulado, inclusive em sua dimensão estética, e os modos como essa circulação atua sobre sua reflexão. Em várias passagens, enalteceu a diversidade do mundo e das pessoas, diversidade que é, ela mesma, objeto de seus estudos e fonte de inspiração.

\section{Palavras-chave}

História da educação comparada - Educação comparada - Jürgen Schriewer.

I- Universidade de São Paulo, 


\title{
Compare: transitive verb; a conversation with Jürgen Schriewer
}

Maria Angela Borges Salvadoril

Maurilane de Souza Biccas

\begin{abstract}
Professor and the director of Comparative Education Center at Humboldt University (Berlin, Germany), recently retired, Jurgen Schriewer is internationally recognized for his studies in comparative education. He was a professor at and the director of Comparative Education Center at Humboldt University, Berlin, Germany, and has recently retired. He was also the director of the Faculty of Education of that institution and president of the Comparative Education Society of Europe. As a visiting professor, he acted in several countries, including France (René Descartes and Paris V universities), Japan (Waseda university, Tokyo) and Argentina (San Andrés university, in Buenos Aires). This interview aims to offer the reader a rare opportunity to learn a little more about the work and the trajectory of a researcher who has focused on this theme for decades. Here, he treats this subject, which is increasingly contemporary and dear to him, in a more informally way. In addition to his professional trajectory and his role in the field of the history of comparative education, Schriewer also shared impressions about the times and places in which he has circulated, including their aesthetic dimension, and about how such movement influences his reflection. In several passages, he praised the diversity of the world and people. Such diversity is the object of his studies and a source of inspiration.
\end{abstract}

\section{Keywords}

History of comparative education - Comparative education - Jürgen Schriewer

\footnotetext{
I- Universidade de São Paulo, São

Paulo, SP, Brasil.

Contacts: mabsalvadori@usp.br;

msbiccas@usp.br
} 


\section{Apresentação}

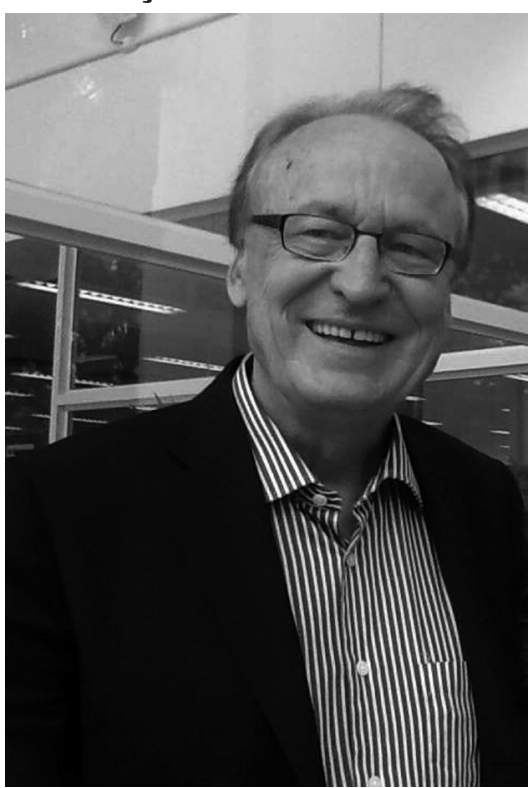

Fonte: arquivos do autor.

Para os pesquisadores do campo da história da educação e, de modo especial, para os que se dedicam aos estudos comparados, o nome do professor Jürgen Schriewer remete, sem dúvida alguma, no Brasil, à obra que ele e António Nóvoa organizaram, intitulada A Difusão Mundial da Escola (2000), de grande repercussão e circulação entre nós. Uma das razões de tal prestígio foi, claramente, o caráter inovador da coletânea em geral e dos textos escritos pelos dois organizadores em particular, uma vez que os trânsitos entre macro e micro-histórias despontavam como caminho frutífero para a compreensão dos processos de escolarização em todo o mundo. A perspectiva então sugerida por Schriewer, colocando sob suspeita a visão neoinstitucionalista predominante desde dos anos 1980 - segundo a qual, ao menos no mundo ocidental, caminhávamos a passos largos para uma homogeneização e uma standartização cultural em todos os setores, inclusive na educação -, bem como a orientação para um enfoque que atentasse às particularidades pertinentes às formas de apropriação da cultura em cada tempo e lugar, renovou os estudos comparados em história da educação e promoveu um olhar que incidia sobre os contextos de recepção e de trocas culturais. No artigo publicado por Schriewer nessa obra, essa hipótese foi construída a partir do exemplo japonês da segunda metade do século XIX e das atividades diplomáticas de Arinori Mori, em 1872, quando foi nomeado chargé d'affaires japonês nos Estados Unidos. Mori encampou as ideias iluministas e liberais do Ocidente e procurou disseminar essa cultura no Japão, propondo um conjunto de reformas educativas para aquele país, com vistas à modernização do sistema escolar japonês. As reformas educacionais da Era Meiji, juntamente com outras reformas econômicas, podem ser vistas como sinal da interdependência internacional e da proliferação de um padrão ocidental de cultura - e de escola - que aos poucos foi atingindo todo o mundo. Contudo, mais do que as aproximações, Schriewer voltou seu olhar para o particular. Segundo ele, o Japão da década de 1880 era diverso daquele dos anos 1870, menos liberal e individualista e mais nacionalista, marcado pela submissão do sujeito ao Estado e por um processo de divinização da figura do imperador. Por isso, paulatinamente, Europa e Estados Unidos foram cedendo lugar à Prússia como sociedade de referência e, em 1885, quando Mori foi nomeado ministro da educação japonês, outra já era também sua aposta, agora enaltecendo mais as ações de Otto von Bismarck. Essa conjuntura específica fez com que as reformas educacionais japonesas da década de 1880 se tornassem, para Schriewer, exemplo desses movimentos que aliam, simultaneamente, sistemas mundiais e realidades particulares, enfatizando tendências autóctones, decorrentes não apenas da centralização política, mas também dos valores e visões de mundo próprios do Japão e dos japoneses. Em outras palavras, tratava-se menos de uma afinidade entre as tradições culturais alemãs e japonesas e mais de uma "situação histórica específica no processo japonês de modernização e ocidentalização" (SCHRIEWER, 2000, p. 118).

Neste e em outros artigos reside uma das hipóteses mais trabalhadas pelo pesquisador 
alemão: a de que as trocas culturais em geral, e as educativas em particular, não acontecem vertical nem passivamente. São mediadas por culturas, tradições e sujeitos locais e por conjunturas históricas específicas, nas quais ganham sentido. Essa hipótese inclui exatamente uma possibilidade teórico-metodológica que concilia o geral, mais pertinente à tradição sociológica, $\mathrm{e}$ o particular, próprio à constituição do campo da história. Nessa hipótese, está também delineada a complexidade desse tipo de trabalho que, simultaneamente, faz da história da educação comparada método e objeto de estudo.

Esse olhar novo, interrogando menos sobre distâncias entre um modelo de referência a ser alcançado e outras realidades ou sobre caminhos unilaterais que aliam educação e desenvolvimento, tem contribuído significativamente para uma onda de pesquisas no campo da história da educação comparada. Nesse sentido, a "difusão mundial" dos trabalhos de Schriewer pode ser encarada em dupla dimensão: ela atesta as conexões relativas à produção de conhecimento, assim como confirma sua hipótese central de que essas conexões não são feitas de forma passiva, adquirindo tons particulares ligados às histórias dos sujeitos e lugares envolvidos nessa produção.

A visita à Faculdade de Educação da Universidade de São Paulo, em outubro de 2013, foi a sua segunda estada entre nós. A primeira, há oito anos, ocorreu por conta de um evento organizado pela Professora Denice Bárbara Catani, titular do Departamento de Metodologia do Ensino e Educação Comparada. Desta feita, em 2013, Schriewer esteve também em outras universidades brasileiras - na Universidade Federal do Ceará, na Universidade de Brasília e na Universidade Metodista de Piracicaba -, além de ter participado da 36. ${ }^{\text {a }}$ Reunião da Associação Nacional de Pós-Graduação e Pesquisa em Educação (ANPEd), realizada na Universidade Federal de Goiás. Sempre tratando das questões da educação e da história da educação comparada, suas falas revelam os motivos pelos quais, nos últimos anos, seu trabalho se tornou uma referência fundamental para os pesquisadores brasileiros envolvidos com temáticas afins.

Inovadoras, suas pesquisas em torno das abordagens sócio-históricas da educação comparada têm procurado mais pela alteridade do que pela generalização. Na contramão de análises que tendem a reconhecer uma espécie de "cultura mundial" pautada pela relação entre educação e desenvolvimento, Schriewer tem atentado ao particularismo e, a partir disso, trabalhado com a noção de "mundos de significado culturalmente específicos", expressão que, de um só golpe, envolve tanto os processos contemporâneos de trocas culturais quanto as múltiplas tradições de sentidos particulares que podem ser atribuídos a essas trocas, numa relação que historiciza o objeto de estudo, o método e a própria noção de cultura aí envolvida (Schriewer, 2013).

Internacionalmente reconhecido por seus estudos em educação comparada, Jürgen Schriewer foi professor e diretor do Centro de Educação Comparada da Universidade de Humboldt, em Berlim, Alemanha, tendo recentemente se aposentado. Foi também diretor da Faculdade de Educação daquela instituição e presidente da Sociedade de Educação Comparada da Europa. Como professor visitante, atuou em vários países, entre os quais França (Universidades René Descartes e Paris V), Japão (Universidade Waseda, em Tóquio) e Argentina (Universidade de San Andrés, em Buenos Aires). Além do alemão, é fluente em francês, inglês e espanhol. Seu envolvimento com tantas línguas - segundo ele, é preciso atentar para a "fuerza interpretativa que sigue residiendo en las semânticas sedimentadas em las lenguas nacionales" (SCHRIEWER, 2013, p. 292) - e tantos paises é, simultaneamente, motivo e sintoma de suas teses principais: apesar da tendência à globalização e à disseminação de uma cultura mundial, os contextos especificos de recepção, com suas histórias, políticas e configurações intelectuais específicas, conferem a essa cultura geral feições particulares. É preciso circular para poder entendê-las. 
Com a entrevista que apresentamos a seguir, esperamos contribuir para o debate acerca da educação comparada em geral e, particularmente, da história da educação comparada, oferecendo ao leitor uma rara ocasião para conhecer um pouco mais a trajetória e o trabalho desse pesquisador que, há décadas focado nessa temática, trata aqui, de maneira mais informal, de uma matéria cada vez mais contemporânea e cara. Além de sua trajetória profissional e seu modo de inserção no campo da história da educação comparada, Schriewer compartilhou também impressões sobre os tempos e lugares pelos quais tem circulado, inclusive em sua dimensão estética. Assim, por exemplo, ao tratar de sua ida para a Universidade de Berlim após a reunificação da Alemanha, expressou sua emoção por estar diante de possibilidades de vida e trabalho antes interditadas. Em várias passagens, enalteceu a diversidade do mundo e das pessoas, diversidade que é, ela mesma, objeto de seus estudos.

A entrevista foi realizada presencialmente, em 11 de outubro de 2013, nas dependências da FEUSP, a partir de um roteiro pré-elaborado, como sugerido pelo próprio autor. Para além dos aportes teóricos e metodológicos, ela revela um profissional apaixonado por seu trabalho, extremamente cordial e generoso em suas colocações. Desse modo, por seus estudos e atitudes, Schriewer continua a ser fonte de inspiração.

Registramos, por fim, que Jürgen Schriewer participa do conselho editorial da revista Educação e Pesquisa.

\section{Referências}

SCHRIEWER, Jürgen. Cultura mundial y mundos de significado culturalmente específicos. Educar em Revista, Curitiba, Brasil, n. 49, p. 275-297, jul./set. 2013.

SCHRIEWER, Jürgen. Estados-modelo e sociedades de referência: externalização em processos de modernização. In. NÓVOA, António, SCHRIEWER, Jürgen (Orgs.). A difusão mundial da escola. Lisboa: EDUCA, 2000, p. 103-120.

Maria Angela Borges Salvadori é professora do Departamento de Filosofia da Educação e Ciências da Educação da Faculdade de Educação da Universidade de São Paulo.

Maurilane de Souza Biccas é professora do Departamento de Filosofia da Educação e Ciências da Educação da Faculdade de Educação da Universidade de São Paulo e coordenadora da área de História e Historiografia da Educação, também da Faculdade de Educação da Universidade de São Paulo. 


\section{Entrevista ${ }^{1}$}

Caro Professor Schriewer, queremos mais uma vez agradecer a oportunidade de realizarmos esta entrevista.

Primeiro, eu gostaria muito de agradecer pelo convite para visitar a Universidade de São Paulo durante a minha passagem pelo Brasil, que começou em Fortaleza, Ceará, onde compareci ao XII Congresso de História da Educação do Ceará. Depois, estive na 36a Reunião Anual da Associação Nacional de PósGraduação e Pesquisa em Educação (ANPEd), em Goiânia; na sequência, estive em Brasília, onde realizei conferências na Universidade Federal de Brasília. Estive ainda em uma conferência e em um bate-papo acadêmico com colegas na Universidade Metodista de Piracicaba (UNIMEP), em São Paulo. Finalmente, cheguei à Universidade de São Paulo. Esta é a minha segunda visita, já que tive a oportunidade de estar aqui há oito anos, quando fui convidado pela professora Denice Catani.

Inicialmente, gostaríamos de saber um pouco mais a respeito de sua formação e trajetória acadêmicas.

Comecei meus estudos universitários na Universidade de Bonn, na Alemanha, até então uma das mais importantes e maiores universidades prussianas e a segunda a ser fundada após a Universidade de Berlim² ${ }^{2}$ Optei por estudar línguas e literaturas alemã e latina, já que temos na Alemanha a concepção de que há certa comunidade de todas as línguas e literaturas de origem latina - do latim popular, que reúne a literatura e língua francesa, italiana, espanhola, portuguesa, romena e, ainda, o catalão, o provençal, segundo as

1- A tradução da entrevista, do espanhol para o português, concedida pelo professor Jürgen Schriewer foi feita por Bruna Heringer de Souza Villar e Rafael Pinto Pinheiro. A eles, nosso agradecimento.

2- A Universidade de Bonn foi fundada em 1818, quando a Prússia era governada por Frederico Guilherme III; A Universidade de Berlim foi fundada em 1810 especialidades e os interesses de investigação de cada catedrático -, chamado "Romanistik", "Romanística”, ou seja, o largo campo das línguas e literaturas de origem latina, vistas de uma perspectiva quase comparativa.

Além disso, tive a sorte de seguir cursos de um catedrático que havia sido recentemente nomeado para a Universidade de Bonn, que me introduziu na carreira da literatura comparada. Ele possuía um profundo conhecimento das literaturas clássicas, românicas e alemãs e gostei muito do enfoque comparativo no campo da literatura. Após dois anos, mudei de universidade, como era o costume na Alemanha da época, para prosseguir meus estudos na Universidade de Würzburg, no norte de Baviera. À época, era uma universidade menor, de dimensões reduzidas, mas me foi oferecida a possibilidade de seguir estudando no campo da língua e literatura alemã, com dois dos mais destacados e conceituados professores em germanística da Alemanha. Um deles trabalhava como professor catedrático de literatura alemã medieval e o outro, como catedrático de literatura moderna. Ambos eram "comparativistas", ou seja, especialistas em literatura comparada. Ambos eram de origem suiça e possuíam um conhecimento estupendo sobre o assunto. Assim, durante toda a minha carreira, desde os meus primeiros estudos universitários, pude participar de cursos, seminários, todos com orientação teórica ligada aos estudos comparados.

Mais tarde, prossegui meus estudos na França, para aprofundar meus conhecimentos em francês, o francês falado, e aprender também sobre os costumes universitários franceses. Fui para a Universidade de Lille, no norte da França. Nessa época, mantive amizade com uma família na cidade de Calais, próxima ao Canal da Mancha, a cidade francesa mais próxima da Inglaterra. Durante os finais de semana, costumava visitar essa família na sua linda casa em Calais.

3- Nota do tradutor: relativo à filologia românica e às transformações históricas do latim vulgar em línguas românicas. 
Quando se deu essa ida para a França?

Comecei meus estudos universitários na década de 1960, no verão ou na primavera de 1962; mudei-me para Würzburg em 1964 e fui para a França em 1965. Pude viver em Lille os primeiros movimentos estudantis que conduziram, mais tarde, como dizem os franceses, aos acontecimentos de maio de 1968.

\section{E o retorno para a Alemanha?}

Voltando a Würzburg, preparei-me para as avaliações daquilo que, na Alemanha, chamava-se e ainda se chama "avaliação do Estado". Consiste em uma prova de conclusão de estudos, muito exigente, que existe para todas as profissões de serviço público e para aquelas para as quais o Estado tem que organizar o nível qualitativo de formação, ou seja, todos os médicos, farmacêuticos, advogados, futuros juízes, professores; todos devem passar por uma avaliação do Estado. Foi instituída na Prússia em 1817 e essa avaliação equivale à "Agregação" na França ${ }^{4}$. Esse nível de estudos normalmente exigia cinco, seis anos; conheci pessoas que estudaram sete, oito anos antes de passarem por essa avaliação.

Cabe dizer que, para se tornar professor de um Liceu, o ginásio na Alemanha, era necessário seguir também os cursos de filosofia e pedagogia. Em Bonn, tive um magnífico professor de filosofia que quase me seduziu para prosseguir estudos nesse campo. Contudo, eu não havia sido aluno de um liceu clássico, ou seja, não havia aprendido latim e grego antigos. Então, os assistentes daquele professor me disseram que não valia a pena prosseguir sem esses conhecimentos. Isso mostra a universidade alemã do pós-guerra e a sua boa e velha tradição.

4 - Para melhor compreensão desses processos citados pelo Prof Schriewer, sugerimos: CAPDEVILLE, Guy. Os sistemas escolares alemão, inglês e francês e a formação de seus professores. Em Aberto, Brasília, ano 14, n. 64, out./dez. 1994, p. 43-60.
Devido à minha estada na França, o catedrático de pedagogia, de ciências da educação da Universidade de Würzburg, encarregou-me de observar as reformas educativas francesas que então se desenvolviam e elaborar um relatório. Efetivamente, fiz um relatório de umas trinta páginas, sendo este o ponto de partida da minha última tese de doutorado. Foi uma tese sobre os problemas e debates da reforma das universidades na França. Para captar bem as estruturas, os problemas estruturais e projetos de reforma, era necessário captar bem também a história das universidades na França, a dualidade entre universidades e instituições de elite e todos os eventos relacionados às revoltas estudantis de maio de 1968.

É uma tese que cobre, mais ou menos, as décadas entre as grandes reformas universitárias da Terceira República até a reforma chamada Reforma Ética Fauroux, de 1996, que conduziu à criação de novas universidades como Paris III e Saint-Denis. Uma reforma experimental, da divisão da antiga Sorbonne em diferentes universidades ditas multidisciplinares. E o mesmo ocorreu em Strasbourg, em Toulouse, em outras grandes cidades universitárias. As universidades existentes eram divididas em dois, três ou até quatro universidades menores, com outro tipo de administração $0^{5}$.

Com essa tese de doutorado, de mais de seiscentas páginas, iniciou-se um trabalho muito importante, que me conduziu para o campo da educação comparada. Quando terminei o trabalho, refleti um pouco sobre qual carreira

\footnotetext{
5- Foi no início da Terceira República francesa, ainda no final do século XIX, que se implantou uma reforma do ensino na França, marcada pela ruptura com a tradição católica e pela defesa da laicidade. Quanto ao segundo marco temporal indicado por Schriewer, trata-se de um conjunto de reformas que ocorreram após a divulgação do relatório Fauroux, em junho de 1996. Roger Fauroux presidiu, a partir de uma nomeação do ministério da educação, entre 1995 e 1996, uma comissão de "notáveis", responsáveis por avaliar o sistema de ensino francês. No relatório, Fauroux apontava aquelas que eram, em sua perspectiva, as principais causas do fracasso da educação francesa em todos os níveis, bem como indicava caminhos para 0 enfrentamento desses problemas. Em relação ao ensino superior, a centralização administrativa, a rígida estrutura hierárquica e as desigualdades regionais eram vistas como empecilhos para o crescimento da universidade. 0 relatório encontra-se publicado: FAUROUX, Roger. Pour l'ecole. Paris: Calmann-Levy, 1996.
} 
escolher, qual disciplina. Para dizer a verdade, foi a educação comparada que me convenceu, por seu caráter empírico de desenvolvimento em diferentes áreas - político-culturais, históricas - e em diferentes condições econômicas, ideológicas, religiosas etc. Digamos, então, que foram os aspectos empíricos e, digamos, da riqueza do mundo, da diversidade de diferentes âmbitos socioculturais, que me convenceram completamente. A partir daí, aprofundei ainda mais meus conhecimentos, ao ministrar meus primeiros seminários e cursos como assistente na Universidade de Würzburg.

Nos anos 1974, 1975, após uma série de publicações, tive a sorte de aceitar, simultaneamente, um posto de professor na Universidade de Frankfurt e em um colégio universitário de formação, sobretudo dos professores, que hoje em dia também é uma universidade. Por minhas orientações anteriores, defini-me como universitário e escolhi a Universidade de Frankfurt.

Àquela época, isso significou um salto enorme, já que a Baviera se considerava como um grande estado mais conservador, com universidades também mais conservadoras, com uma forte hierarquia de professores, assistentes, alunos etc. Frankfurt, que está localizada no grande estado de Hesse, colocava-se de uma forma contrária em relação a esse conservadorismo. Foi em Frankfurt que aconteceram as revoltas estudantis mais violentas como, por exemplo, as lutas pela conservação de casas antigas; em alguns casos, os estudantes conseguiram obter a conservação de um patrimônio históricourbanístico riquíssimo. Frankfurt era uma cidade linda antes da guerra, mas seu centro foi completamente destruído pelos bombardeios. Contudo, em alguns bairros mais distantes, foram mais ou menos preservadas preciosas casas com estilo neoclássico, do século XIX.

Houve essa moda de reformas arquitetônicas pautadas pela modernização, dominada por nomes - que, aliás, são muito conhecidos pela construção de Brasília - como Niemeyer, Mies van der Rohe, Hans Scharoun, entre outros, que compõem uma geração de arquitetos mais ou menos afiliados à Bauhaus. E, ainda antes desse período, ou seja, antes da II Guerra, Le Corbusier. Eles seguiam uma visão completamente diferente de cidade. Quiseram demolir tudo o que ainda existia para transformar a cidade em uma paisagem ondulada, com algumas torres e edifícios isolados, conectados entre si por grandes avenidas. 0 próprio Le Corbusier também teve a ideia de destruir completamente o centro histórico de Estocolmo, mesmo o que não havia sido destruído pela guerra, para transformá-lo a partir dessa nova concepção de arquitetura urbanística moderna.

0 que quero dizer é que Frankfurt, nessa época, foi uma cidade com muitos movimentos e debates. Também a filosofia crítica da escola de Frankfurt estava desempenhando certo papel, bem como a política escolar dos diferentes partidos. Havia uma paisagem social, econômica, escolar, de política escolar e universitária, em constante movimento. Eu e minha mulher mudamos de Frankfurt, onde vivi alguns anos, e mais tarde fomos morar nos arredores da cidade. Foi um período rico, que me permitiu desenvolver mais meus próprios pensamentos e investigações, já que o caos significa liberdade [Não é verdade?]. E eu tive bastante liberdade para prosseguir com meus próprios interesses de investigação.

E quanto às orientações teóricas? Quais os principais autores e as principais perspectivas teóricas com as quais, ao longo desse tempo, tem dialogado?

Nesse período, li com muito interesse alguns grandes autores que me influenciaram, entre eles Karl Popper e seus grandes debates metateóricos. A tradição popperiana do racionalismo crítico e os escritos de Popper em geral, que foram transferidos para o campo das ciências sociais por um filósofo-sociólogo alemão dessa época, professor Hans Albert, sempre me convenceram mais. 
Aquele foi também um momento de intensas lutas políticas e ideológicas em Frankfurt, em meio às quais procurei ter uma posição clara e elaborada. Interessei-me também, cada vez mais, pelo pensamento de Émile Durkheim, como sociólogo que trabalha com comparação, de maneira que li quase todas as grandes obras durkheimianas, tanto que, em Frankfurt, acabei desenvolvendo, com um colega, um projeto histórico-comparativo sobre a emergência e o desenvolvimento do campo disciplinar da educação nas universidades da França, Alemanha e Itália.

Esse projeto foi subvencionado e financiado, com bastantes recursos, pela Fundação Volkswagen. A companhia Volkswagen repassa certa porcentagem de seus lucros para uma fundação destinada a subvencionar investigações em todos os campos de conhecimento. Naquela época, passei muito tempo em Paris, trabalhando nos arquivos históricos franceses, e me lembro disso com muito prazer. Para um investigador com interesses históricos, estar sentado em um arquivo torna-se um dos momentos mais deliciosos. A cada manhã, despertava como um caçador afoito para realizar sua tarefa.

Ao longo dos quinze anos que passei como professor de educação comparada na Universidade de Frankfurt, descobri publicações e livros de outro grande sociólogo alemão, Niklas Luhmann. Segundo seus estudiosos, Luhmann se situa na tradição das teorias de sistemas. Contudo, ele insiste sobre o aspecto autorreferencial, auto-organizativo dos sistemas sociais, inserindo-se também em outra corrente de pensamento, muito mais sofisticada, alimentada por neurofisiólogos chilenos ligados à teoria dos arranjos auto-organizativos. Luhmann desenvolveu-a com o termo autorreferência. Também essa teoria possui uma dimensão histórica bem marcante, que diz respeito ao desenvolvimento dos grandes sistemas sociais em suas dimensões política, científica, religiosa, econômica e, mais tarde, educativa. Trata-se de uma teoria da diferenciação funcional na sociedade moderna e de um marco teórico de grande interesse, tanto histórico como teórico, que permite conceituar investigações histórico-comparadas de maneira muito elegante. Então, para sintetizar, Popper, Durkheim e Luhmann compõem uma série de autores que muito me influenciaram, embora existam outros.

Mais recentemente, durante os anos que passei em Berlim, li bastante alguns dos representantes do chamado neoinstitucionalismo sociológico, como os professores John Meyer, do Departamento de Educação da Universidade de Stanford, nos Estados Unidos, e Francisco Ramirez, professor de educação comparada, do Instituto de Sociologia dessa mesma instituição. Ambos acumularam, durante mais de 20 anos, um repertório teórico riquíssimo, com conceitos que abrangem diferentes campos de conhecimento como a educação, o direito moderno, os direitos humanos, a questão ambiental, de gênero, os processos crescentes de individualização, o indivíduo na sociedade moderna, incluindo ainda o direito à diferença sexual ${ }^{6}$. Durante uma visita pelo campus de Stanford, John Meyer e Francisco Ramirez me apresentaram, com bastante orgulho, um monumento que mostrava dois garotos se beijando. Com um pouco de ironia, perguntaram-me: "Você consegue imaginar isso em uma universidade europeia?".

Bem, essa é a série, digamos, dos principais autores com os quais aprendi muito. Porém, com muitas leituras e em constantes debates com outros, inclusive sobre esses autores aqui nominalmente citados, também aprendi a tomar minhas próprias decisões e a desenvolver certas posições críticas, sobretudo no que diz respeito ao neoinstitucionalismo sociológico ${ }^{7}$.

6- Como se constata no site da Graduate School of Education, de Stanford, os dois professores citados aqui trabalham com perspectivas comparadas nos campos da educação e da sociologia.

7- 0 neoinstitucionalismo sociológico, que obteve uma repercussão mais ampla nos anos 1980 e 1990, não constitui um bloco homogêneo. Embora centrado nas relações entre instituições e comportamentos, bem como nos modos pelos quais as instituições surgem e se modificam, ele abrange uma ampla gama de estudos com suportes teóricos bem diversos, que vão desde o funcionalismo até o marxismo. No campo específico da sociologia, a repercussão dos estudos neoinstitucionais está ligada principalmente a 
Imaginamos que essas leituras tenham se dado em função de projetos de pesquisa então em desenvolvimento.

Sim, essas leituras e debates vão ocorrendo simultaneamente ao andamento de uma série de projetos de investigação. Por exemplo, estudando a emergência e o desenvolvimento da educação ou das ciências da educação como disciplina universitária, dediquei-me à leitura de Durkheim. Lembrome com muito prazer de ter encontrado, em seu dossiê no Arquivo Nacional de Paris, algumas cartas escritas de próprio punho, uma escrita muito fina, com tinta violeta, algo que é muito raro. Tudo era de uma estética muito delicada. Então, foi um prazer não só teórico e histórico mas também estético ter em mãos essas peças preciosas, as cartas pessoais de Durkheim.

Ao mesmo tempo, havia conseguido, junto com outro colega, um projeto de história comparada dos sistemas de formação profissional ou de capacitação profissional na França e na Alemanha. É possível notar que meus primeiros grandes projetos e trabalhos sempre utilizam a comparação franco-alemã, que representa dois países vizinhos, porém com instituições, tradições de pensamento e ideologias muito diferentes, já que tiveram sua configuração final em uma época de profundo antagonismo entre eles, antagonismo esse fundado pela Revolução Francesa e Napoleão no que diz respeito ao aspecto constitucional e, mais tarde, antagonismo político mesmo, inclusive criado por instituições educativas e de ensino superior também muito diferentes.

Contribuí em projetos sobre a história da pedagogia em ambos os países e participei de um pequeno grupo europeu em uma investigação sobre as universidades europeias, um pequeno grupo dirigido por um historiador francês,

um olhar diferenciado e inovador para as instituições e organizações, olhar esse que envolve e mesmo prioriza uma dimensão das práticas culturais e seus símbolos. Com base em HALL, Peter A., TAYLOR, Rosemary C. R. As três versões do neoinstitucionalismo. Lua Nova, São Paulo:CEDEC, n. 58, v. 23, p. $193-223$.
Christophe Charle ${ }^{8}$ E recordo muito bem que, depois de trabalharmos juntos três, quatro, cinco anos, demo-nos conta, com plena consciência, de que os alemães pensavam de maneira geral em disciplinas, uma ao lado da outra, enquanto os franceses pensavam em uma hierarquia, do Colégio de França, Escola Normal Superior e a Universidade, uma hierarquia que era também uma hierarquia entre Paris, o centro da antiga Sorbonne, e a província. Para os franceses, tratava-se de analisar cada categoria, nessas diferentes filiações hierárquicas. Para os alemães, as questões eram: Como se define uma disciplina? Como se pode captar as características daquilo que constitui uma disciplina?

No decorrer do tempo, o autorrecrutamento das cátedras, a criação de revistas próprias, a justaposição entre os autores responsáveis por disciplinas e que produzem e publicam artigos nas revistas também indicavam muitas diferenças entre as "ciências da educação" (como eram chamadas na França) e a "pedagogia acadêmica" da Alemanha. Tudo isso permitia pesquisas muito significativas. Mais tarde, em 1991, devido à reunificação da Alemanha, ocorrida em 3 de outubro de 1990, tive a oportunidade de me apresentar como candidato a uma nova cátedra de educação comparada, criada na Universidade de Humboldt, que é a antiga Universidade de Berlim, fundada por volta de 1800, situada na Avenida Unter den Linden, o endereço mais privilegiado que se pode ter na Alemanha.

Depois do concurso, junto com dois colegas das ciências da educação e outro colega muito reconhecido no campo da história, estive entre os quatro primeiros professores catedráticos novamente nomeados para a Universidade de Humboldt, em uma cerimônia na grande sala do Reitor, o qual fazia um discurso sobre a constituição federal e a constituição da cidade-estado de Berlim, e pensei comigo mesmo: quantos anos se

8- Professor de História Contemporânea da Universidade Paris I, centrado nos temas da história comparada na Europa, história cultural e história social nos séculos XIX e XX. 
passaram nesta sala desde a última vez em que foi apresentado um sermão com a fórmula "conto que Deus me ajude a manter meus compromissos”. É uma fórmula que, hoje, os sujeitos estão livres para incorporar ou não. Naquela ocasião, entre nós quatro que éramos nomeados, dois concordavam e dois não. Mas, durante mais de sessenta anos de ditadura na Alemanha, essa escolha não tinha sido possível.

Como foram esses primeiros anos em Berlim e como decorreram suas pesquisas a partir da ida para a Universidade de Humboldt?

Os primeiros anos em Berlim foram repletos de problemas de reorganização do departamento da faculdade. Também fui responsável, durante certo tempo, pela reconstrução das carreiras junto à Faculdade de Educação e pelo recrutamento de outros professores. Esta última atividade foi realizada por meio de uma comissão composta, em nível nacional - o que era uma exceção -, por reconhecidos especialistas das ciências da educação de diferentes universidades da Alemanha, encarregados de reestruturar o futuro departamento da Faculdade de Educação e avaliar as pessoas em seus cargos, além de fazer os convites para novas candidaturas. Foi sobretudo em Berlim que mais se desenvolveu um projeto de pesquisa destinado a examinar e, em certa medida, criticar as bases nas quais se formaram essas instituições. Um grande projeto, se comparado com o desenvolvimento dos saberes pedagógicos contidos nas revistas mais reconhecidas e representativas de três unidades de análise: Europa Ocidental, representada por Espanha; Europa Oriental, pela Rússia ou União Soviética, conforme as décadas; e o mundo confuciano, representado pela China.

Buscamos, então, as revistas mais importantes durante nove décadas para chegarmos à conclusão de que existem grandes oscilações dentro dos discursos nacionais, oscilações entre a abertura e o fechamento nacional. Essas oscilações são muito grandes para serem compatíveis com as teorias neoinstitucionalistas que pretendem delimitar um quase exponencial de crescimento da internacionalidade. Também houve diferenças muito grandes entre os discursos nacionais de cada unidade, incompatíveis com as teorias neoinstitucionalistas que pretendem que exista uma espécie de isomorfia.

No decorrer da pesquisa, diferentes aspectos vão contradizendo os argumentos neoinstitucionalistas. Nesse sentido, notei que, cada vez mais, uma contribuição fundamental das investigações comparadas - tanto em educação como nas ciências sociais mais gerais - é a função critica de análise baseada na diversidade de contextos histórico-sociais. Como bem disse um especialista, "a variedade das situações humanas é tão grande que não se resume facilmente a algumas ideologias educativas para certos programas unilineares de educação ou a certas teorias que também planejam o desenvolvimento unilinear". Então, a variedade do mundo, a riqueza do mundo é um desafio que importa a todas as ideologias, programas e teorias.

Nesse contexto, surgiu um debate, também no campo teórico da comparação, que levou às minhas últimas publicações, um debate com os autores neoinstitucionalistas. Esses proêmios também significam ou designam os desafios da educação comparada como campo científico, do mesmo modo como as ciências sociais têm que superar desafios importantíssimos no que se refere à construção de suas teorias, atravessados pelas relações causa-efeito gerais ou pela noção de causalidade múltipla. 0 próprio Durkheim era defensor do princípio da causalidade unilinear inerente às ciências naturais de seu tempo. Mas todo o campo das disciplinas, reflexões, filosofias e pesquisas sobre os sistemas auto-organizativos foi ampliando essa noção, detalhando a causalidade múltipla e afirmando, entre outras coisas, que tanto uma causa mínima pode produzir efeitos enormes quanto podem existir efeitos sem causas e causas que não têm nenhum efeito.

Quais são, em sua opinião, os principais desafios colocados aos estudos de educação comparada hoje? 
Lembro-me aqui muito bem de um bom amigo meu, um historiador de origem alemã, que fez toda a sua carreira universitária nos Estados Unidos, autor de obras importantíssimas sobre a história da ciência na França e sobre a história comparada de instituições de ensino secundário e superior na França e na Alemanha, além de alguns capítulos sobre a Inglaterra e os Estados Unidos. Lembro-me muito bem como esse autor fez a anotação do manuscrito que eu lhe havia entregado, escrevendo “não!”. Com isso, quero dizer que se tratava de um problema muito debatido - esse das teorias e sistemas autorreferenciais, auto-organizativos -, um problema teórico e um desafio tanto para a história quanto para as ciências sociais.

Esse é um dos grandes desafios postos à educação comparada. Outro desafio é a crescente emergência do que se pode chamar, em uma sociedade mundial, de entrelaçamento de relações de intercâmbio e comunicação em todos os âmbitos da ação social. Assim, como se podem realizar investigações comparadas quando o mundo está todo entrelaçado, como uma grande rede? É nesse sentido que me interessavam também as teorias neoinstitucionalistas, bem como as necessárias modificações que precisam ser introduzidas nesses novos marcos teóricos.

Tudo isso significa que a educação comparada não é um campo fácil. Muitos de meus colegas pensam que é a coisa mais fácil do mundo, como se fosse apenas ficar um período de três semanas em outro país, fazer algumas entrevistas e depois, rapidamente, publicar um artigo. Eu penso - considerando a riqueza e a variedade do mundo e suas tradições históricas, as complicações teóricas do pensamento comparativo, todas as teorias autorreferenciais, que são bastante complicadas - que a educação comparada é um campo muito difícil, que também requer conhecimento em diferentes línguas, de modo que se permita compreender o significado, mesmo quando traduzido para o inglês. Isso também é um desafio enorme não só para a educação comparada ou investigação comparada, mas também um desafio enorme para todos os países, todas as políticas educativas etc.

0 conhecimento das línguas é fundamental. Afinal, os grandes informes do Banco Mundial, da Comissão Europeia, todos os acordos, são em inglês; os termos essenciais são termos em inglês. Esses termos já carregam suas próprias experiências coletivas, memórias e práticas de pensamento; não são neutros, embora pareçam ser. Por exemplo, entre os anos 1960 e 1980, ocorreram muitas pesquisas sobre a profissão docente, sobre a profissionalização dos educadores, dos professores. Esse tema emergiu na Inglaterra a partir da sociologia das profissões, mas uma profissão é uma coisa na Grã-Bretanha e outra na Europa continental.

Uma vez, fiz uma experiência durante meu primeiro curso de educação comparada na Universidade de San Andrés, em Buenos Aires, na Argentina, e me apresentei com um cartão de visitas. Percebi que tal procedimento gerou uma série de dúvidas e, depois, expliquei as diferenças entre um cartão de visitas típico da França, um cartão típico das Ilhas Britânicas, Alemanha etc. Para isso, usei o mesmo nome e sobrenome em todos os exemplos e indiquei os problemas que o desconhecimento da língua e da história pode acarretar. Expliquei que, na França, existe o título “agrégé de l'université" (agregado/associado à universidade), que não tem nada a ver com uma universidade específica como, por exemplo, a USP, mas com a concepção napoleônica de que o sistema educativo total era a "Universidade da França". E "agrégé de l'université" é um tipo de professor hierarquicamente superior, do ensino secundário ou das classes preparatórias para as grandes escolas; alguém que conseguiu obter uma vaga em um dos exames altamente competitivos dos quais falamos no início. Pode haver dez mil candidatos, mas, se existem somente oitocentas vagas, somente oitocentos podem passar; os demais são desprezados. Isso exemplifica o sentido francês de concurso, de exame competitivo e, por essa razão, sem valor em outros países, via de regra desconhecido. Mas, na França, significa muito. No caso mais extremo, existem nome e sobrenome e outras indicações, 
como o símbolo da Escola Politécnica - um "x" -, famosa instituição criada em fins do século XVIII. Esse "x", esse símbolo, aliás, vale muito mais que um título universitário.

Nesse sentido, existem desafios que se colocam a todas as disciplinas, mas que também se põem a todas as políticas educativas, já que está na moda adaptar rapidamente tudo que vem do mundo anglo-saxão imaginário. Cada vez mais utilizamos termos em inglês sem pensar nos conteúdos que possuem.

Há outro aspecto importante dessa dimensão linguística que gostaria de destacar: há algumas semanas, li o resumo de um artigo dizendo que, nos últimos quinze anos, os livros da área de relações internacionais publicados e utilizados nos Estados Unidos têm usado como referência bibliográfica, basicamente, outros textos de língua inglesa. Ora, com isso, perdem conhecimento do mundo e das próprias relações internacionais que discutem. Perdem conhecimento do mundo na medida em que se baseiam, quase que exclusivamente ou na grande maioria dos casos, em fontes de língua inglesa. De maneira que, hoje em dia, temos um campo muito mais centrado no mundo anglo-americano que nos anos 1970 ou 1960. Quando se considera que, em muitos casos, esses trabalhos são traduzidos para o português e utilizados em muitas universidades daqui e de outros lugares do mundo, estamos diante de uma redução do conhecimento da riqueza desse mundo, o que é um aspecto dramático. 0 mesmo se pode constatar em relação às revistas. Existem duas grandes revistas de educação comparada: a Compared Education Review, publicada nos Estados Unidos, e a Compared Education, publicada na Inglaterra. Nas duas, 90\% das referências bibliográficas são de língua inglesa, inclusive quando certos autores tratam da África ou da Europa Ocidental.

Junto com a língua, tais publicações transportam suas próprias noções como, por exemplo, quando falam em "mercado" nas análises dos sistemas universitários do continente europeu.
Eu próprio critiquei muitos artigos apresentados para a Compared Education Review, escritos por autores britânicos, que usavam indiscriminadamente certos termos, desconsiderando as singularidades de significados que esses termos podem abarcar quando interpretados por leitores de outra comunidade linguística. Essa é uma das razões pelas quais me esforço um pouco com o espanhol, já que ele é a única língua de origem europeia capaz de rivalizar, de competir, com o inglês; o francês já se perdeu. Nos grandes congressos internacionais, não se fala mais o francês e, quando eventualmente há alguns especialistas da França presentes, com seus manuscritos em francês, rapidamente têm que retornar ao hotel e, durante a noite, fazer a tradução para o inglês.

Penso, então, que temos pela frente esses três grandes desafios: o desafio da complexificação da teorização, particularmente no campo das ciências sociais, já que se refere a tudo que abrange o social autorreferencial; o desafıo da globalização, da mundialização do mundo; e o terceiro, o problema das línguas.

Como avalia a presença da disciplina de educação comparada no currículo dos cursos de formação de professores?

Por tudo o que foi dito anteriormente, percebe-se que não é tarefa fácil introduzir os temas da educação comparada na formação de professores. Mas ela é um importante instrumento crítico para que os alunos tenham plena consciência de que programas, ideologias, doutrinas pedagógicoeducativas não se aplicam da mesma forma a diferentes contextos, a uma realidade muito mais multifacetada. A inclusão da educação comparada no currículo dos cursos de formação de professores pode contribuir para a relativização de uma série de noções preconcebidas. E essa é exatamente a tarefa da pesquisa educacional de qualidade: destruir noções preconcebidas, abrir a mente. 


\section{Obras do autor disponiveis em português e espanhol’}

SCHRIEWER, Jürgen., KAELBLE, Hartmut Eds). La comparación en las ciencias sociales e históricas: un debate interdisciplinar. Barcelona \& México: Octaedro, 2010

SCHRIEWER, Jürgen; PEDRÓ, Francesc (Orgs.). Manual de educación comparada: teorías, investigaciones, perspectivas. v. 2. Barcelona: PPU, 1993.

SCHRIEWER, Jürgen; NÓVOA, António (Orgs.). A difusão mundial da escola. Lisboa: EDUCA, 2000.

SCHRIEWER, Jürgen; MARTINEZ, Carlos. Ideología educativa mundial o reflexión idiosincrática? El discurso pedagógico en España, Rusia (Unión Soviética) y China del siglo XX. Revista de Educación, Madrid, n. 343, p. 531-577, maio-ago. 2007.

SCHRIEWER, Jürgen. Cultura mundial y mundos de significado culturalmente específicos. Educar em Revista, Curitiba, n. 49, p. 275-297, jul./set. 2013. a UFPR.

SCHRIEWER, Jürgen. El método comparativo y la necesidad de externalización: criterios metodológicos y conceptos sociológicos. In: SCHRIEWER, Jürgen; PEDRÓ, Francesc (Orgs.). Manual de educación comparada: teorías, investigaciones, perspectivas, v.

2. Barcelona: PPU, 1993, p. 189-251.

SCHRIEWER, Jürgen. Formación del discurso en la educación comparada. Barcelona: Ediciones Pomares, 2002.

SCHRIEWER, Jürgen. Formas de externalização no conhecimento educacional. Lisboa: Educa, 2001.

SCHRIEWER, Jürgen. Internacionalidades múltiples: surgimiento de una ideología à nivel mundial y persistencia de visiones idiosincráticas mundiales. En: CHARLE, Christophe; SCHRIEWER, Jürgen; WAGNER, Peter (Comps.). Redes intelectuales trasnacionales: formas de conocimiento académico y búsqueda de identidades culturales. Barcelona; México: Pomares, 2007. p. $359-408$.

SCHRIEWER, Jürgen. Sistema mundial y redes de interrelación: la internacionalización de la educación y el papel de la investigación comparada. In: CARUSO, Marcelo; TENORTH, Heinz-Elmar (Comps.). Internacionalización. Políticas educativas y reflexión pedagógica en un medio global. Buenos Aires: Granica, 2011. p. 41-105.

\section{Em outras línguas:}

SCHRIEWER, Jürgen, HOLMES, Brian (Eds). Theories and methods in comparative education. Frankfurt am Main: Peter Lang, 1988.

SCHRIEWER, Jürgen; CHARLE, Christophe; KEINER, Edwin (Eds.) Sozialer raum und akademische kulturen. Studien zur europäischen Hochschul- und Wissenschaftsgeschichte im 19. und 20. Jahrhundert. / A la recherche de l'espace universitaire européen. Etudes sur l'enseignement supérieur aux XIXe et XXe siècles, Komparatistische Bibliothek, v. 3. Frankfurt am Main: Peter Lang, 1993.

SCHRIEWER, Jürgen; HARNEY, Klaus. Beruflichkeit versus Culture technique: Pour une sociogenèse de la sémantique du travail en France et en Allemagne. In: DIDRY, Claude; WAGNER, Peter; ZIMMERMANN, Bénédicte (Eds). Le Travail et la Nation. Histoire croisée de la France et de l'Allemagne à l'horizon européen. Paris: Editions de la Maison des Sciences de l'Homme, 1999, p. 107-146.

SCHRIEWER, Jürgen; KAELBLE, Hartmut (Eds). Vergleich und transfer. komparatistik in den geschichts-, sozial- und kulturwissenschaften. Frankfurt am Main; New York: Campus, 2003.

SCHRIEWER, Jürgen; KEINER, Edwin. Communication patterns and intellectual traditions in educational sciences: franceand Germany. Comparative Education Review, v. 36, n.1, pp. 25-51, 1992.

SCHRIEWER, Jürgen; MARTINEZ, Carlos. Constructions of Internationality in Education. In: G. Steiner-Khamsi (Ed.). The global politics of educational borrowing and lending. New York: Teachers College Press, 2004, p. 29-53.

9- De antemão, desculpamo-nos no caso de ausência de alguma outra referência aqui não indicada. 
SCHRIEWER, Jürgen (1999). Coping with complexity in comparative methodology: issues of social causation and processes of macro-historical globalisation. In. ALEXANDER, Robin; BROADFOOF, Patricia; PHILLIPS, David. (Eds.). Learning from Comparing: New directions in comparative educational research. Oxford: Cambridge University Press, 1999, p. 42-43 (vol. 1).

SCHRIEWER, Jürgen (Ed.). Discourse formation in comparative education. Frankfurt am Main: Peter Lang, 2003.

SCHRIEWER, Jürgen (Ed.). Weltkultur und kulturelle bedeutungswelten. Zur globalisierung von bildungsdiskursen, eigene und fremde welten. Frankfurt am Main \& New York: Campus, 2007.

SCHRIEWER, Jürgen (Ed.). Comparative methodologies in the social sciences - cross-disciplinary inspirations. Comparative Education, n. 32. London: Routledge, p. 299-336, 2006.

SCHRIEWER, Jürgen; BRUNO-JOFRÉ, Rosa (Comps.). The global reception of John Dewey's thought: multiple refractions through time and space. New York; London: Routledge, 2012.

SCHRIEWER, Jürgen; BRUNO-JOFRÉ, Rosa (Org.). Encounters on education/ Encuentros sobre educación/ Rencontres sur l'éducation. Kingston, Ontario: Queen's University, Faculty of Education, Kingston, Ontario: Queen's University, Faculty of Education, v. 10, fall/otoño/automne 2009.

SCHRIEWER, Jürgen; KEINER, Edwin. Erneuerung aus dem geist der eigenen tradition? Über kontinuität und wandel nationaler denkstile in der erziehungswissenschaft. Revue Suisse des Sciences de l'éducation, v. 22, n. 1, p. 27-50, 2000.

SCHRIEWER, Jürgen; NÓVOA, António. History of Education. In: International enciclopedia of social and behavioral sciences. Oxford: Helsevier, 2001, p. 4217-4233, v. 6.

SCHRIEWER, Jürgen; UCHS, Eckhardt (Comps.). Internationale Organisationen als Global Players in Bildungspolitik und Pädagogik. Zeitschrift für Pädagogik, v. 53, n. 2, p. 145-223, 2007.

SCHRIEWER, Jürgen; CARUSO, Marcelo (Comps.). Nationalerziehung und universalmethode: frühe formen schulorganisatorischer globalisierung. Leipzig: Leipziger Universitätsverlag, 2005.

SCHRIEWER, Jürgen; HARNEY, Klaus. Beruflichkeit versus Culture technique: pour une sociogenèse de la sémantique du travail en France et en Allemagne. In: DIDRY, Claude; WAGNER, Peter; ZIMMERMANN, Bénédicte. Le travail et la nation: histoire croisée de la France et de l'Allemagne à l'horizon européen. Paris: Editions de la Maison des Sciences de l'Homme, 1999. p. 107-146.

SCHRIEWER, Jürgen; KEINER, Edwin; CHARLE, Christophe (Comps.). Sozialer raum und akademische kulturen / a la recherche de l'espace universitaire européen. Fráncfort del Meno: Peter Lang, 1993.

'rationalized myths' in european higher education: the construction and diffusion of the Bologna model, European Education, v. 41, n. 2, p. 31-51, 2009.

"Reference societies and model constructions: questioning international policy studies". In: HESSE, Joachim-Jens; LANE, Jan-Erik; NISHIKAWA, Y. (Eds.). The public sector in transition: East Asia and the European Union compared. Baden-Baden: Nomos, 2007, p. 85-102.

SCHRIEWER, Jürgen. "Wie global ist institutionalisierte Weltbildungsprogrammatik?". In: HEINTZ, Bettina; MUNCH, Richard; TYRELL, Hartmann (Eds). Weltgesellschaft: theoretische zugänge und empirische problemlagen. Stuttgart: Lucius \& Lucius, 2005, p. 415-441 (Special issue n. 1 of Zeitschrift für Soziologie).

Berlin: Le collège, cet inconnu... In: VIALLANEIX, Paul; ELMOZNINO, Rosette (Eds.). L'apprentissage du savoir vivant: bicentenaire de la fondation de l'ecole normale supérieure - fonctions des grands collèges européens. Paris: Presses Universitaires de France, 1995, p. 135-140.

Comparative education methodology in transition: towards a science of complexity? In. SCHRIEWER, J. (Ed.). Discourse formation in comparative education. Frankfurt am Main: Peter Lang, 2003, p.3-52.

Comparative social science: characteristic problems and changing problem solutions. In: Comparative methodologies in the social sciences: Cross-Disciplinary Inspirations, 2006, p. 299-336. 
SCHRIEWER, Jürgen. Education comparée. In: BEILLEROT, Jacky; MOSCONI, Nicole (Eds). Traité des sciences et des pratiques de l'éducation. Paris: Dunod, 2006, p. 145-158.

. Educational studies in Europe. In: SCHRIEWER, Jürgen; SWING, Elizabeth Sherman; ORIVEL, François (Eds.). Problems and prospects in European education. Westport; London: Praeger, 2000, p. 72-95.

L'Éducation comparée: mise en perspective historique d'un champ de recherche. Revue Française de Pédagogie, 121, 1997, p. 9 - 27.

. L'Education comparée: un programme ambitieux face à de nouveaux defies. In: LADERRIÈRE, Pierre., VANISCOTTE, Francine (Eds.). Education comparée: un outil pour l'Europe. Paris: L'Harmattan, 2003, p. 21-55.

L' internationalisation des discours sur l'éducation: adoption d'une «idéologie mondiale» ou persistance du style de «réflexion systémique» spécifiquement nationale?. Revue Française de Pédagogie, v. 146, n. 1, 2004, p. 7-26.

SCHRIEWER, Jürgen. Multiple Internationalities: The emergence of a world-level ideology and the persistence of idiosyncratic world-views. IN: SCHRIEWER, Jürgen; CHARLE, Christophe; WAGNER, Peter (Eds.). Transnational intellectual networks. Forms of academic knowledge and the search for cultural identities. Frankfurt am Main; New York: Campus, 2004, p. 473-533.

Remodelling social order through the conquest of public space: myths, ceremonies and visual representations in revolutionary societies. Leipzig: Leipziger Universitätsverlag, 2009.

Wie global ist institutionalisierte Weltbildungsprogrammatik? Neo-institutionalistische thesen im licht kulturvergleichender analysen. In: HEINTZ, Bettina; MÜNCH, Richard; TYRELL, Hartmann (Comps.). Weltgesellschaft: theoretische zugänge und empirische problemlagen. Stuttgart: Lucius \& Lucius, 2005. p. 415-441.

World-System and Interrelationship Networks: The Internationalization of education and the role of comparative inquiry. In POPKEWITZ, Thomas (Ed.). Educational Knowledge: changing relationships between the state, civil society, and the educational community. New York: SUNY Press, 2000, p.305-343. 